\title{
Flux-switching PM Brushless Machines with Alternative Stator and Rotor Pole Combinations
}

\author{
A. Thomas ${ }^{1}$, Z. Q. Zhu ${ }^{2}$, G. W. Jewell ${ }^{3}$, and D. Howe ${ }^{4}$ \\ ${ }^{1}$ Department of Electrical and Electronic Engineering, University of Sheffield, Elp05ast@sheffield.ac.uk \\ ${ }^{2}$ Department of Electrical and Electronic Engineering, University of Sheffield, Z.Q.Zhu@sheffield.ac.uk \\ ${ }^{3}$ Department of Electrical and Electronic Engineering, University of Sheffield, G.Jewell@sheffield.ac.uk \\ ${ }^{4}$ Department of Electrical and Electronic Engineering, University of Sheffield, D.Howe@sheffield.ac.uk
}

\begin{abstract}
New flux-switching permanent magnet (FSPM) brushless machine topologies with different stator and rotor pole combinations $\left(N_{s} / N_{r}\right)$ are developed, with potentially reduced stator and rotor pole numbers without introducing the unbalanced magnetic force. The relative merits of FSPM and flux reversal permanent magnet (FRPM) brushless machines are evaluated. The electromagnetic performance, including back-emf, static torque, cogging torque, stator and rotor iron losses and magnet eddy current loss, and unbalanced magnetic force, etc. of new FSPM machines having $N_{s} / N_{r}=12 / 16$ and 6/8 is also compared with that of existing FSPM machines having $N_{s} / N_{r}=12 / 10$ and 6/5 by finite element analyses and experiments.
\end{abstract}

\section{Keywords} brushless machines, doubly salient, flux reversal, flux
switching, permanent magnet brushless machines, doubly salient, flux reversal, flux
switching, permanent magnet

\section{INTRODUCTION}

Flux-switching permanent magnet (FSPM) machines have been a popular research topic due to high power density and robust rotor structure [Hoang et al., 1997; Zhu et al., 2005]. With both PMs and armature windings on the stator and a robust single piece rotor similar to the switched reluctance machine, the FSPM machines are well suited to high speed applications, Figure 1(a). The use of high energy PMs on the stator and the flux focusing effect of the ' $\mathrm{C}$ '-core modular stator topology

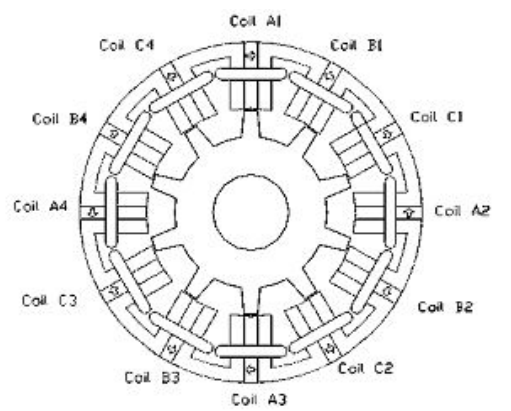

(a) $12 / 10$ FSPM

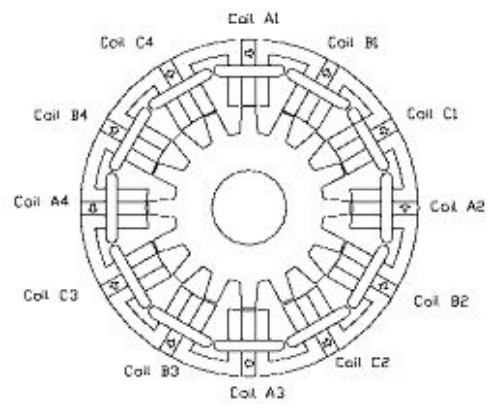

(b) $12 / 16$ FSPM
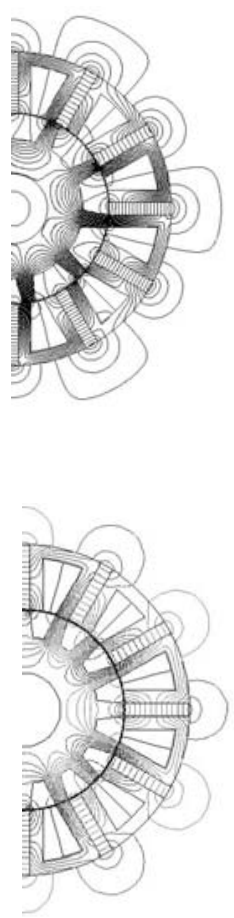

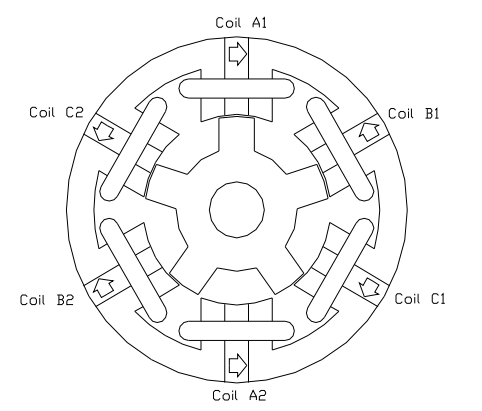

(c) 6/5 FSPM
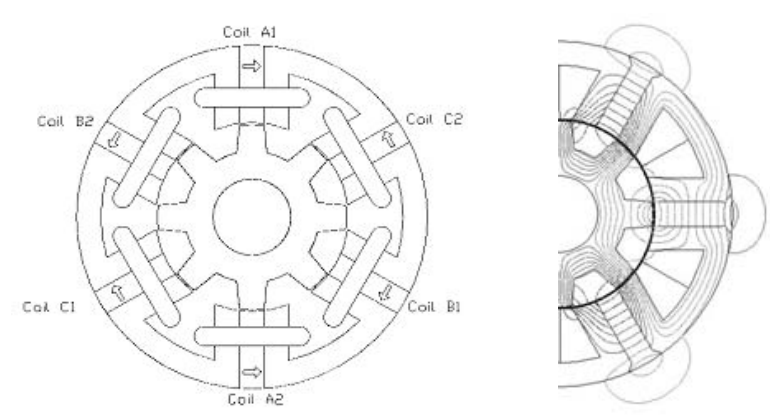

(d) 6/8 FSPM

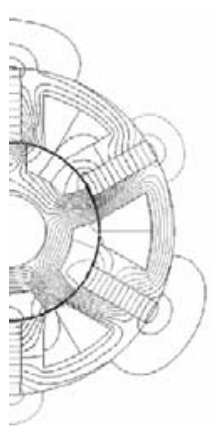

Fig. 1 Alternative FSPM machines with different $\mathrm{N}_{s} / \mathrm{N}_{\mathrm{r}}$ 


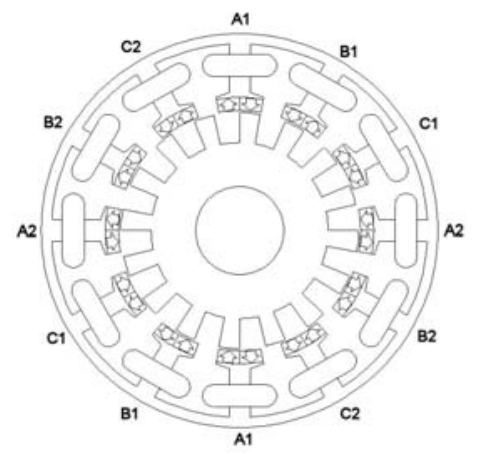

(a) $12 / 16$ FRPM

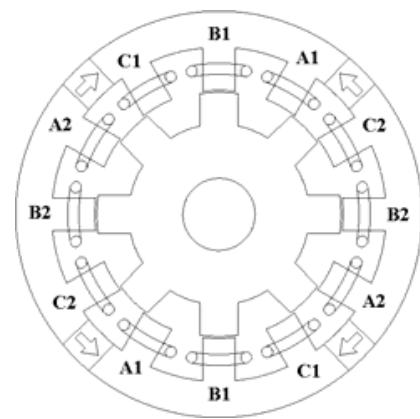

(b) $12 / 8$ DSPM

Fig. 2 Schematic of doubly salient machine topologies other than FSPM

result in high airgap flux density, together with bi-polar winding flux-linkage, which is desirable in torque dense machines.

Other doubly-salient machine topologies include the flux-reversal PM machine (FRPM) and doubly-salient PM machines (DSPM) [Boldea et al., 1999; Wang et al., 1999; Liao et al., 1995; Hua et al., 2005; Amara et al., 2003], Figure 2. They share the traits of FSPM machines, in that they have a salient pole rotor without any coil or PM, and a salient stator containing the PMs and armature windings. The electromagnetic performance of FSPM and DSPM machines has been compared in [Hua et al., 2005]. It shows that the FSPM machine can have significant higher torque density than that of the DSPM machine in which the flux-linkage is uni-polar. The operating principles of the FRPM and FSPM are very similar in that each stator pole has a "north" and a "south" that provides a bipolar flux linkage in a concentrated coil, Figure 1(a) and Figure 2(a). Although they operate on the same principles, existing FSPM and FRPM machines have different stator to rotor pole combinations, e.g. $\mathrm{N}_{\mathrm{s}} / \mathrm{N}_{\mathrm{r}}=12 / 10$ for FSPM and $\mathrm{N}_{\mathrm{s}} / \mathrm{N}_{\mathrm{r}}=12$ / 16 for FRPM for 3-phase topologies according to the design guidelines set out in [Hoang et al., 1997] and [Boldea et al., 1999]. In this paper, 3-phase 12/10 FSPM and 12/16 FRPM will be first compared and a new FSPM machine topology is then developed. The electromag- netic performance of four FSPM machines with $\mathrm{N}_{\mathrm{s}} / \mathrm{N}_{\mathrm{r}}$ $=12 / 10,6 / 5,12 / 16$ and 6/8, as shown in Figure 1, is compared by finite element analyses and validated by experiments.

The new topology provides a new dimension to the 3phase FSPM motor by reducing the fundamental frequency and complexity of the stator. This allows the consideration of 3-phase FSPM topology in high speed applications with regards to lower losses without the torque ripple penalties of using single or 2-phase FSPM topologies [Hua et al., 2005; Chen et al., 2006]. With the 6/8 FSPM topology an improved torque output can be achieved while maintaining the torque density of the 3-phase FSPM topology.

\section{COMPARISON OF OTHER DOUBLY-SALIENT PERMANENT MAGNET TOPOLOGIES WITH FSPM MACHINES}

The three types of doubly-salient permanent magnet machine topologies can be seen in Figure 1(a) and Figure 2. It shows that they share common themes in that they all have PMs and concentrated armature windings in the stator and a salient rotor. The differences lie in the arrangement and quantity of the PM material within the stator, which determines the characteristics of the motor topologies. The FSPM machine uses more PM material and it is utilised through flux focusing to achieve large airgap flux densities, Figure 3, providing relatively high torque densities with considerable cost penalty, though ferrite magnets may be used with flux focusing [Amara et al., 2003]. The FRPM topology has the PMs on the stator tooth surfaces, Figure 1(a), and contains less PM material than the FSPM machine. The airgap flux density is limited by the PM remanence $\mathrm{B}_{\mathrm{r}}$, although it induces the bi-polar flux linkage desired in high power dense machines. The DSPM machine contains the least PM material of the three topologies, and is essentially a switched reluctance machine with permanent magnets located between phase coils within the stator back iron

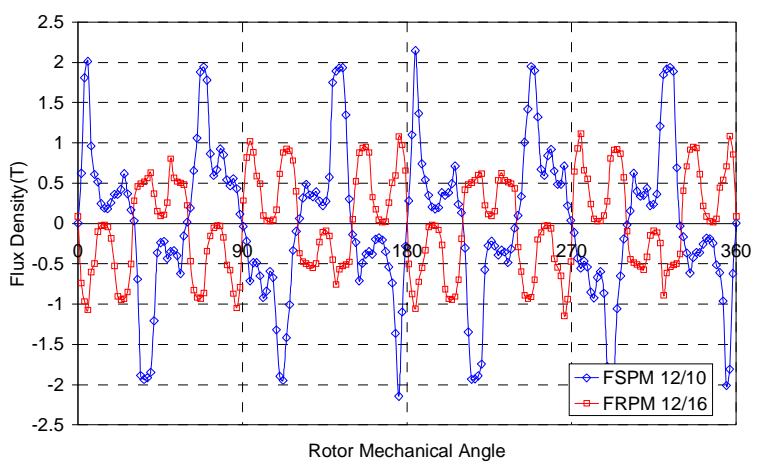

Fig. 3 Airgap flux densities of 12/10 FSPM and 12/16 FRPM machines 
resulting in a uni-polar flux linkage. The attributes of the DSPM machine is compared with the FSPM machine (for a 2-phase) in [Hua et al, 2005], and therefore will not be considered in further depth within this paper. The FRPM machine can be compared on a like to like basis of a 12/16 and 12/10 machines. From the design of both topologies it can clearly be seen that the FSPM machine will have the advantage of flux focusing, Figure 3, providing a higher flux linkage and back-EMF constant than the FRPM machine, resulting in a higher torque density for the FSPM machine, Figure 4, Figure 5, and Figure 6.

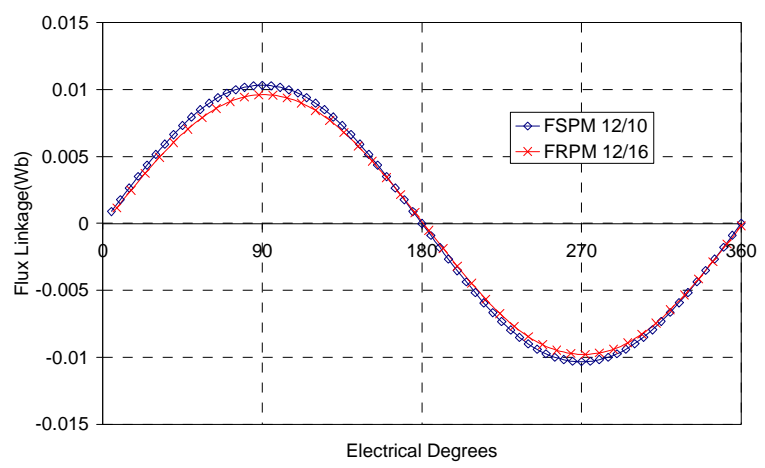

Fig. 4 Flux linkages of 12/10 FSPM and 12/16 FRPM machines

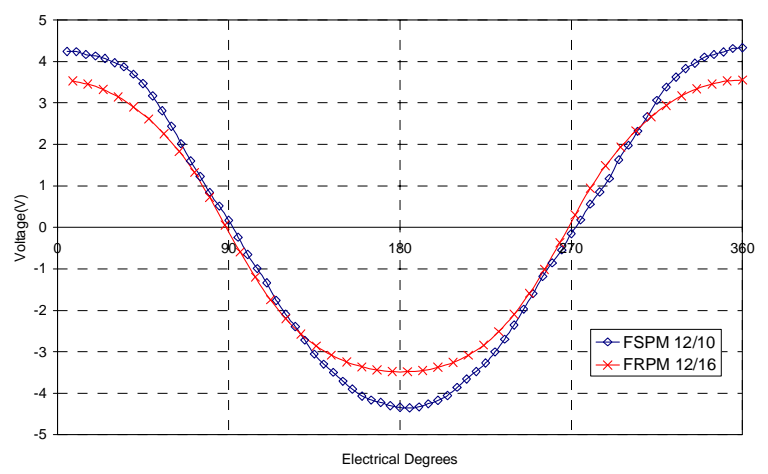

Fig. 5 Back-EMFs of 12/10 FSPM and 12/16 FRPM machines

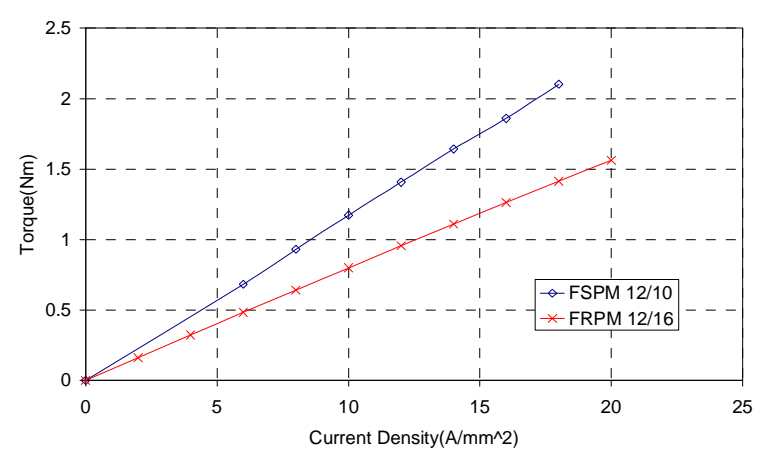

Fig. 6 Torque vs current of 12/10 FSPM and 12/16 FRPM machines
However the FRPM machine has the advantage of being able to reduce its electrical frequency by halving the number of stator and rotor poles to $6 / 8$ providing a reduced fundamental frequency, which is not possible with the FSPM 12/10 machine without introducing the unbalanced rotor force in the 6/5 FSPM machine. However, as both machines operate on the same principles, it was decided to increase the rotor pole number of the FSPM machine from 10 to 16 so that 6/8 FSPM can be realized without any inherent unbalanced magnetic force.

\section{COMPARATIVE STUDY OF ALTERNATIVE FLUX-SWITCHING PERMANENT MAGNET MACHINES}

The four aforementioned FSPM machines are designed and prototyped, Figure 7, with the same leading dimen-

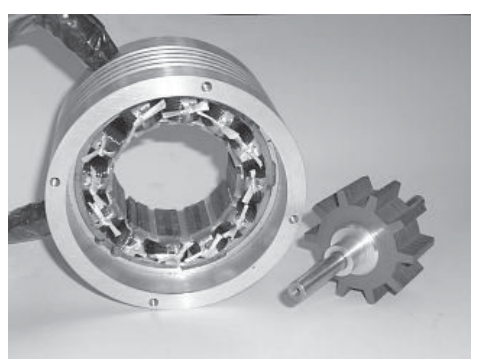

(a) $12 / 10$ FSPM

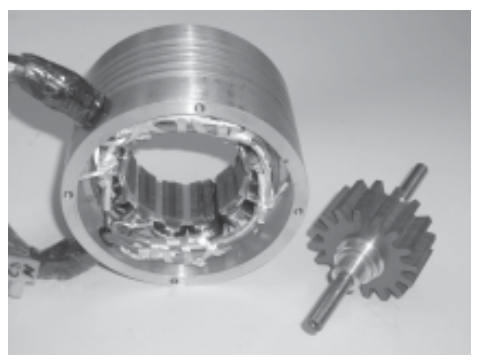

(b) $12 / 16$ FSPM

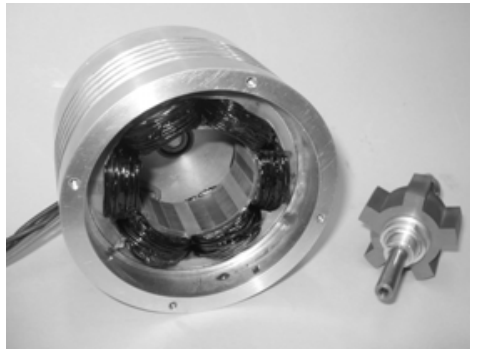

(c) 6/5 FSPM

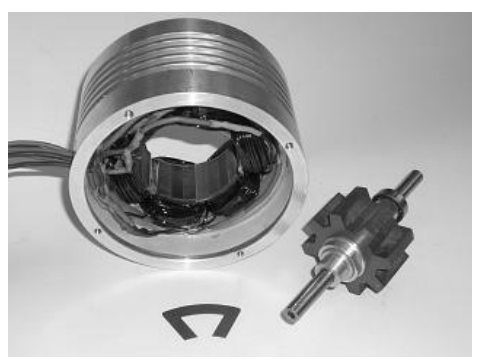

(d) 6/8 FSPM

Fig. 7 Prototype FSPM motors 
Table 1 Leading dimensions of prototype FSPM machines

\begin{tabular}{|c|c|c|c|c|}
\hline $\mathrm{N} / \mathrm{N}_{t}$ & $12 / 10$ & $12 / 16$ & $6 / 5$ & $6 / 8$ \\
\hline Stator OD, mm & \multicolumn{5}{|c|}{90} \\
\hline Number of Phase & \multicolumn{5}{|c|}{3} \\
\hline No. of Stator Slots & \multicolumn{2}{|c|}{12} & \multicolumn{2}{|c|}{6} \\
\hline No. of Rotor Teeth & 10 & 16 & 5 & 8 \\
\hline Axial Length, mm & \multicolumn{5}{|c|}{45} \\
\hline Winding Number & \multicolumn{5}{|c|}{64} & \multicolumn{2}{|c|}{64} \\
\hline Airgap Length, mm & \multicolumn{5}{|c|}{1.2} \\
\hline Magnet Remanence, T & \multicolumn{5}{|c|}{} \\
\hline
\end{tabular}

Fig. 8 Airgap flux density of 6/5 and 6/8 FSPM machines

sions given in Table 1. The electromagnetic performance, e.g. airgap field, back-emf, cogging torque, winding inductance and static torque, are analyzed by finite element method and validated by experiments. The airgap flux density for both 6/5 and 6/8 machines are displayed in Figure 8 and show the increased numbers of peaks due to the increased rotor pole numbers. The decreased flux linkage due to the flux leakage resulting from the increase in rotor poles of the 12/16 and 6/8 motors are offset due to the increase in electrical frequency, hence back-EMF being comparable. Therefore, the number of turns per phase can be maintained the same for both rotor topologies hence the same stator was used.

The predicted and measured back-EMF waveforms are shown in Figure 9 and for all the compared FSPM machines and it is clear that influence of 3D effect is greater in the 12 slot stator topologies. This maybe explained by the increased magnet width within the 6 slot stator and hence increasing the reluctance of the flux leakage paths within the stator which cause considerable end effects [Zhu et al., 2007].

The cogging torques of all prototypes were measured and predicted by the finite element analysis. They have a reasonably close correlation, Figure 10 . However, it was found that the cogging torque is very sensitive to the stator assembly of the motor.

The static torques of both 12 slot topologies are compared in Figure 11, with both machines having similar

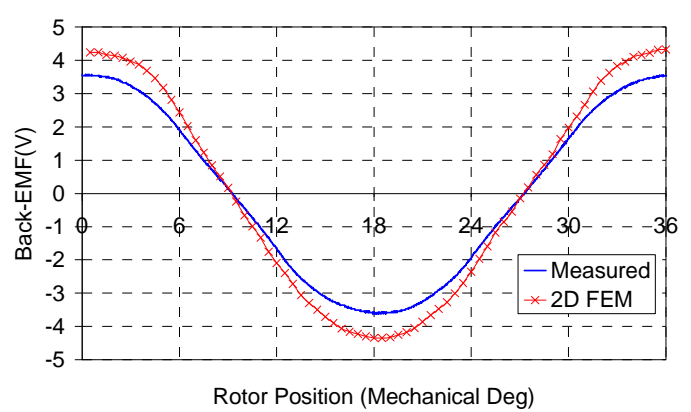

(a) $12 / 10$ FSPM

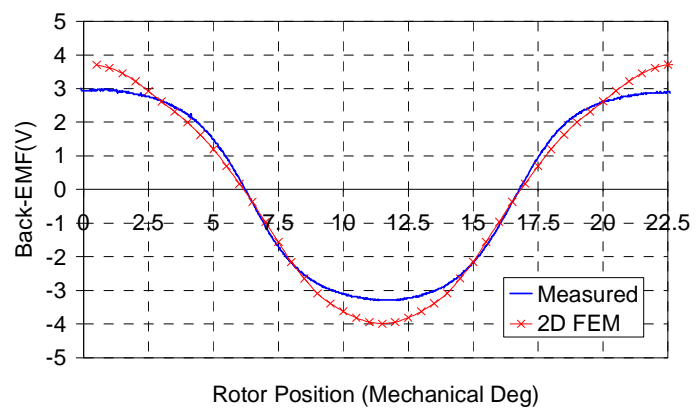

(b) $12 / 16$ FSPM

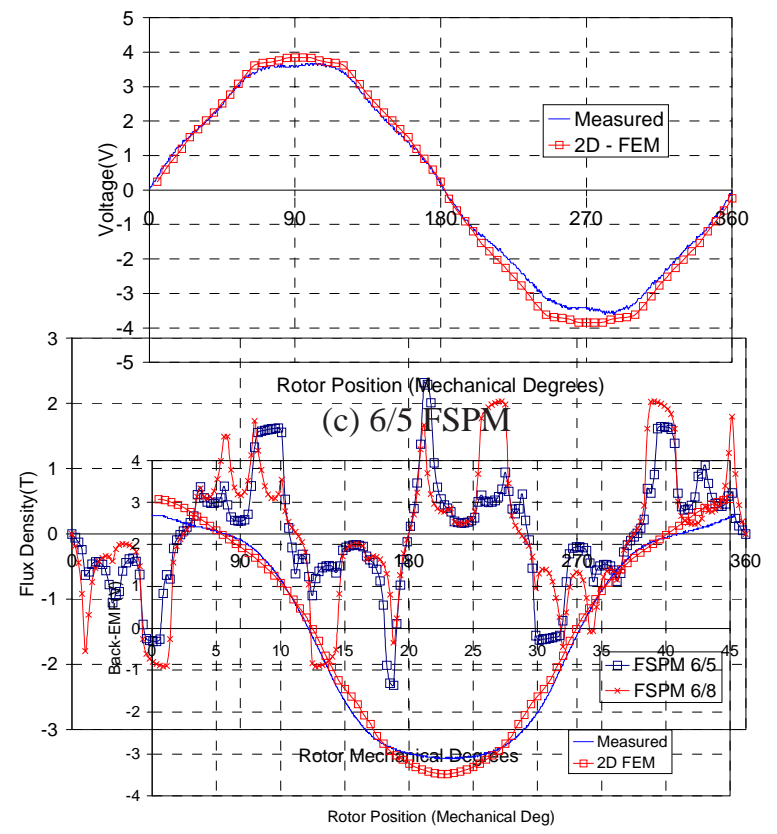

(d) $6 / 8$ FSPM

Fig. 9 Measured and predicted back-EMF at 400rpm

torque output although the 12/16 motor suffers from the drop in flux linkage. The static torques of both $6 / 5$ and 6/8 FSPM machine were analyzed by finite element method and then measured in order to confirm the torque capability of both machines. From Figure 12, it can be seen that $6 / 5$ machine has a higher torque ability when compared to the 6/8 machine although both are comparable to the 12 slot stator topologies, hence showing no significant decrease due to reducing pole numbers. 


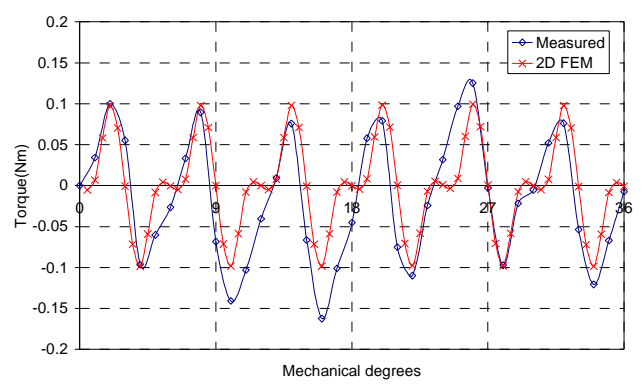

(a) 12/10 FSPM

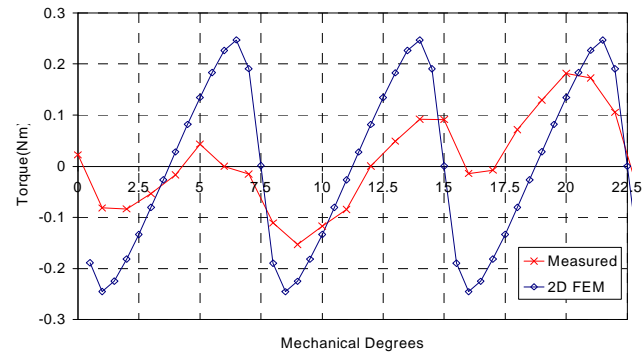

(b) $12 / 16$ FSPM

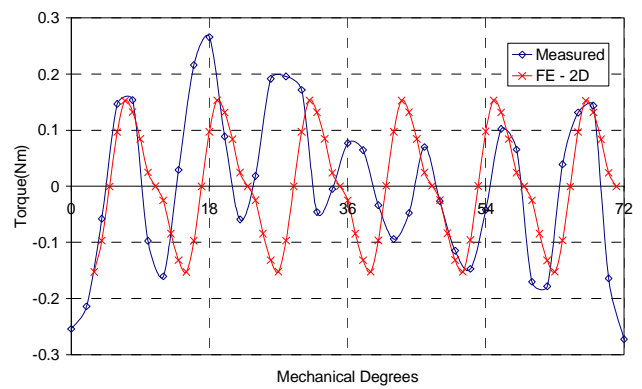

(c) 6/5 FSPM

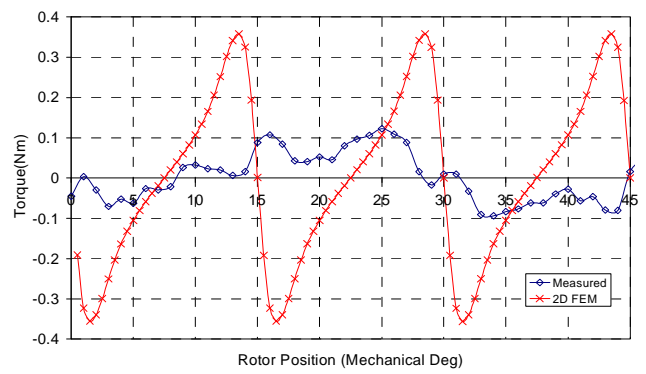

(d) 6/8 FSPM

Fig. 10 Measured and predicted cogging torque for FSPM motors

\section{LOSSES IN FSPM MACHINES}

As stipulated within the previous sections of this paper, the primary reason for reducing the number of poles is to reduce the fundamental frequency whilst maintaining the torque capabilities of the 3-phase FSPM machine. With this in mind the iron losses and the permanent magnet eddy current losses were analysed using methods previously used in the loss prediction of FSPM machines [Pang et al., 2007]. Within FSPM machines, it has been shown that the magnet eddy loss may contribute a large part of the total machine losses due to the

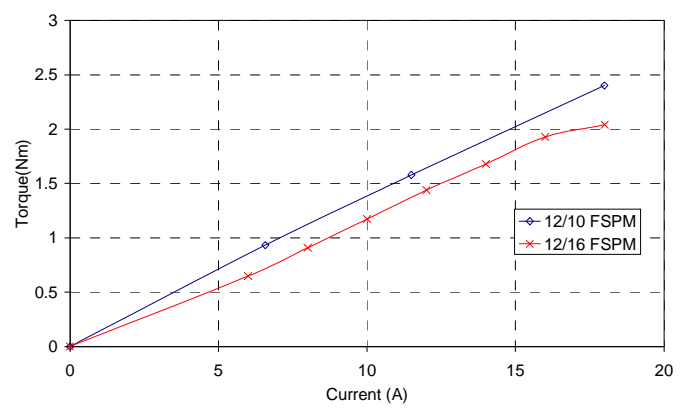

Fig. 11 Measured average static torques of 12/10 and 12/16 FSPM motors

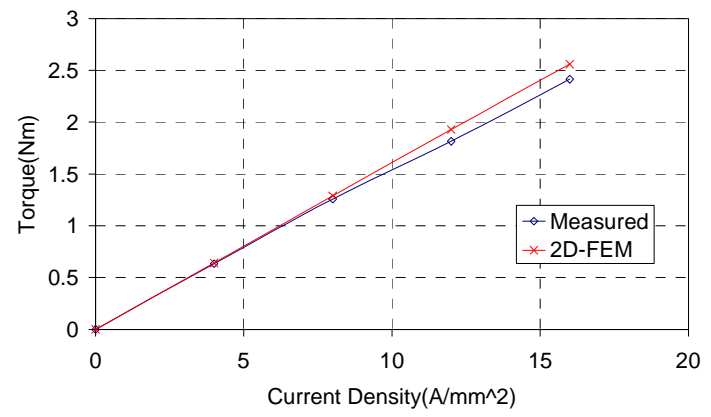

(a) 6/5 FSPM

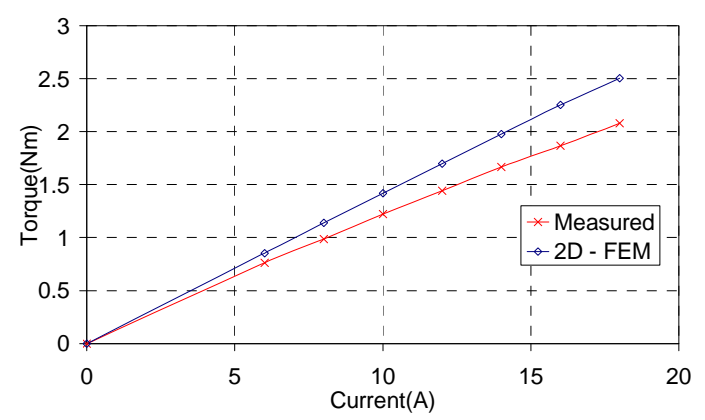

(b) 6/8 FSPM

Fig. 12 Measured and predicted average static torques of 6/5 and 6/8 FSPM motors

volume of magnet material within the motor topology. However, radial and/or axial segmentation of the permanent magnets can reduce the magnet eddy losses significantly [Zhu et al., 2007]. However, this makes the machine more complex to manufacture and therefore increases cost. Therefore, it would be beneficial to be able to decrease the losses within the permanent magnet and reduce the total losses of the machine.

The iron losses of the FSPM machines are dominated by the flux due to the permanent magnet, the armature flux only causing a marginal increase in iron loss in the constant torque region [Pang et al., 2007]. Therefore, only open-circuit iron and magnet eddy losses in all three topologies are considered. It is clear that the 6 slot machines benefit from the reduced fundamental frequency 


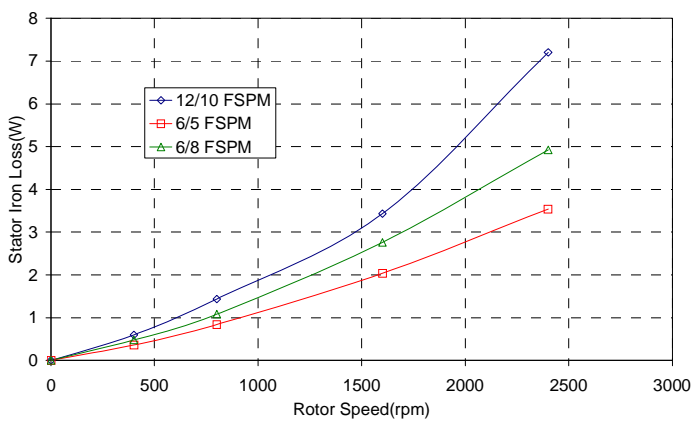

Fig. 13 Stator iron loss in the FSPM machines on open circuit conditions

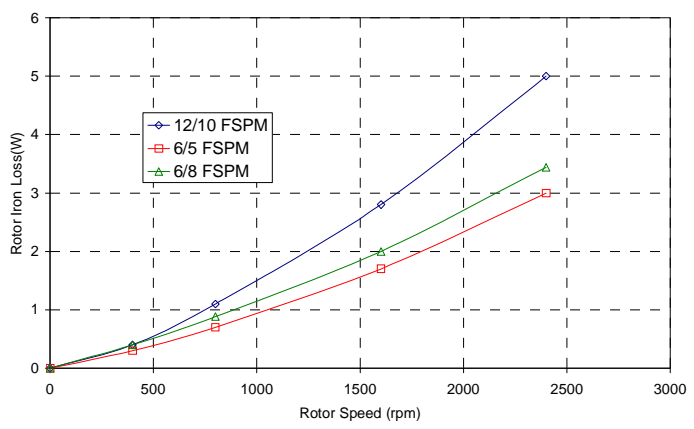

Fig. 14 Rotor iron loss in FSPM machines on open circuit conditions

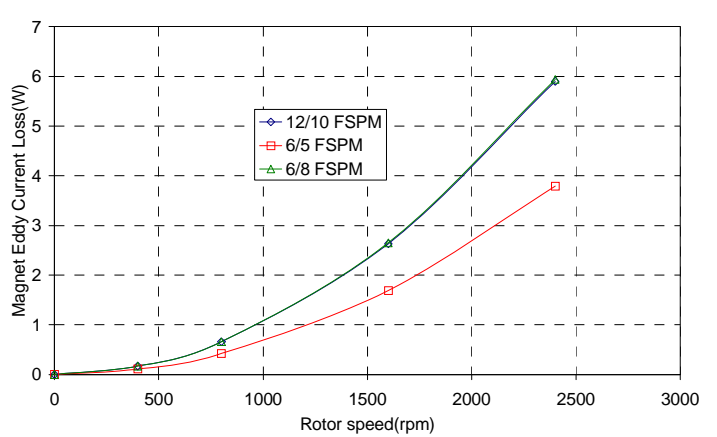

Fig. 15 Magnet eddy current losses within FSPM topologies

with iron losses reduced within the FSPM 6/5 and 6/8 motors by $\sim 52 \%$ and $~ 33 \%$ in the stator and $\sim 40 \%$ and $\sim 32 \%$ in the rotor, respectively, Figure 13 and Figure 14.

In terms of magnet eddy losses, the 12/10 and 6/8 FSPM have the same losses even though the fundamental frequency is reduced, Figure 15. This is due to the increase in individual magnet area, meaning larger eddy currents can circulate, opposing the effect of fundamental frequency drop within the 6/8 FSPM.

\section{UNBALANCED MAGNETIC FORCE ON 6/5 ROTOR}

As previously mentioned in the introduction, the 6/5 FSPM topology has considerable unbalanced magnetic forces acting on the rotor due to the asymmetry of the 5 pole rotor. This will induce vibrations within the machine under operating conditions resulting in reducing the bearing life and unwanted noise and vibration forces on the rotor shaft which would be onerous in high speed applications. Noise and vibrations within PM machines have been investigated previously for rotor eccentricity and asymmetric phase windings in fractional slot PM machines [Wang et al., 1999; Zhu et al., 2007; Chen et al., 2006]. In these papers analytical methods are used to accurately estimate the forces applied to the rotor. However, due to the doubly salient nature of the FSPM machine, an accurate analytical model would be time consuming hence finite element analysis was used.

Figure 16 shows the unbalanced magnetic forces that are applied to the 6/5 FSPM rotor in the $\mathrm{x}$ and $\mathrm{y}$ direction in comparison to the 6/8 FSPM machine. It can be seen there are significant forces applied to the rotor under open circuit conditions due to the asymmetry of the rotor and is increased with the Rotor Pole Ratio (RPR, a ratio of rotor pole width to stator pole width, which is defined as 1 when equal to the stator tooth width). The

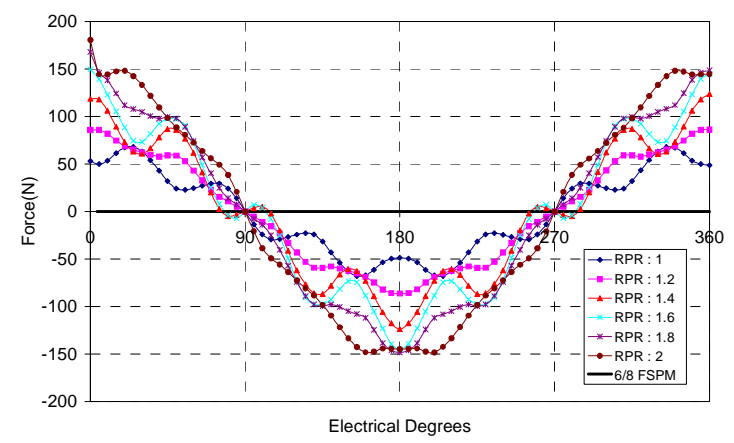

(a) X-axis force

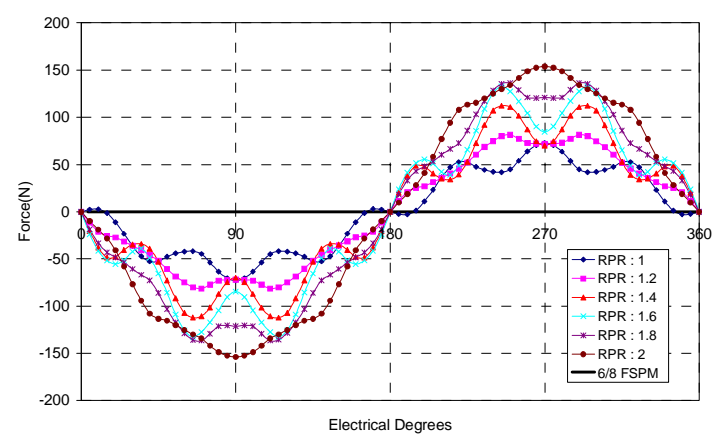

(b) Y-axis force

Fig. 16 Open circuit unbalanced magnetic force on rotor of 6/5 and 6/8 FSPM motors 


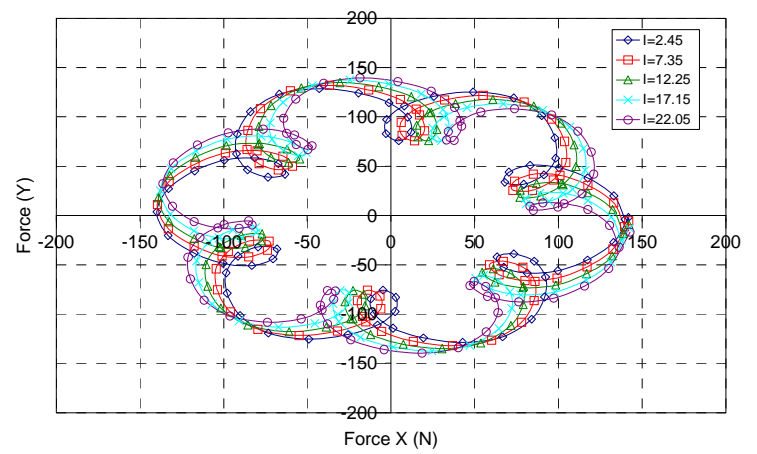

Fig. 17 Unbalanced magnetic force for different applied currents on rotor of 6/5 FSPM motors

6/8 FSPM has a symmetrical rotor and therefore does not suffer from the unbalanced magnetic forces, providing a viable alternative machine topology when compared to the 6/5 FSPM motor. When the current is applied to the 6/5 FSPM motor, the magnitude of the rotor force is not significantly changed, although the phase of the force rotation is slightly altered, Figure 17.

\section{CONCLUSIONS}

Alternative 3-phase FSPM motor topologies with potentially reduced stator pole number without introducing the unbalanced magnetic force are presented. The reduced pole number allows for a smooth torque output associated with the 3-phase FSPM along with the reduced fundamental frequency and machine complexity. This would facilitate the use of 3-phase FSPM machines in high speed applications allowing for reduced machine losses without the noise and vibrations that would accompany the 6/5 FSPM machine topology.

The optimal combination of stator and rotor pole numbers in flux-switching PM machines is addressed separately in [Chen et al., 2008].

\section{References}

Amara, Y., E. Hoang, M. Gabsi, M. Lecrivain, and S. Allano, Design and comparison of different fluxswitch synchronous machines for an oil breather application, European Transactions on Electrical Power, Vol. 15, 497-511, 2005.

Boldea, I., C. Wang, and S. A. Nasar, Design of a threephase flux reversal machine, Electrical Machines and Power Systems, Vol. 27, 849-863, 1999.

Chen, Y., Z. Q. Zhu, D. Howe, and Y. Y. Ye, Starting torque of single-phase flux-switching permanent magnet motors, IEEE Transactions on Magnetics, Vol. 42, No. 10, 3416-3418, 2006.

Chen, Y. S., Z. Q. Zhu, and D. Howe, Vibration of permanent magnet brushless machines having a fractional number of slots per pole, IEEE Transactions on Mag- netics, Vol. 42, No. 10, 3395-3397, 2006.

Chen, J. T., Z. Q. Zhu, A. Thomas, and D. Howe, Optimal combination of stator and rotor pole numbers in flux-switching PM brushless AC machines, to be presented at International Conference on Electrical Machines and Systems, 17-20 October, 2008, Wuhan, China.

Hoang, E., A. H. Ben-Ahmed, and J. Lucidarme, Switching flux permanent magnet polyphased synchronous machines, 7th European Conference on Power Electronics and Applications, Vol. 3, 903-908, 1997.

Hua, W., Z. Q. Zhu, M. Cheng, Y. Pang, and D. Howe, Comparison of flux-switching and doubly-salient permanent magnet brushless machines, Proceedings of Eighth International Conference on Electrical Machines and Systems, Nanjing, China, 165-170, 2005.

Liao, Y., F. Liang, and T. A. Lipo, A permanent magnet motor with doubly salient structure, IEEE Transactions on Industry Applications, Vol. 31, No. 5, 10691078, 1995.

Pang, Y., Z. Q. Zhu, D. Howe, S. Iwasaki, R. Deodhar, and A. Pride, Investigation of iron loss in flux-switching permanent magnet machines, Proceedings of International Conference on Power Electronics, Machines and Drives, IET, York, UK, 460-464, 2008.

Wang, C., S. A. Nasar, and I. Boldea, Three-phase flux reversal machine, IEE Proceedings-EPA, Vol. 146, No. 2, 139-146, 1999.

Wang, J. P., and D. K. Lieu, Magnetic lumped parameter modeling of rotor eccentricity in brushless permanent-magnet motors, IEEE Transactions on Magnetics, Vol. 35, No. 5, 4226-4231, 1999.

Zhu, Z. Q., Y. Pang, D. Howe, S. Iwasaki, R. Deodhar, and A. Pride, Analysis of electromagnetic performance of flux-switching permanent magnet machines by non-linear adaptive lumped parameter magnetic circuit model, IEEE Transactions on Magnetics, Vol. 41, 4277-4287, 2005.

Zhu, Z. Q., D. Ishak, D. Howe, and J. T. Chen, Unbalanced magnetic forces in permanent magnet brushless machines with diametrically asymmetric disposition of phase windings, IEEE Transactions on Industry Applications, Vol. 43, No. 6, 1544-1553, 2007.

Zhu, Z. Q., J. T. Chen, Y. Pang, R. Owen, G. W. Jewell, D. Howe, S. Iwasaki, and R. Deodhar, Analytical modelling of end-effect on electromagnetic torque in flux-switching permanent magnet machine, Proceedings of International Conference on Electrical Machines and Systems, Seoul, Korea, 943-948, 2007.

Zhu, Z. Q., Y. Pang, J. T. Chen, R. Owen, D. Howe, S. Iwasaki, R. Deodhar, and A. Pride, Analysis and reduction of magnet eddy current loss in flux-switching permanent magnet machines, Proceedings of In- 
A. Thomas et al.: Flux-switching PM Brushless Machines with Alternative Stator and Rotor Pole Combinations

ternational Conference on Power Electronics, Ma-

chines and Drives, IET, York, UK, 120-124, 2008.

(Received May 5, 2008; accepted June 5, 2008) 